\title{
Head support for the patient during ophthalmic microsurgery
}

\author{
DERMOT PIERSE and ARTHUR D. MaG. STEELE \\ Croydon Eye Unit
}

The increasing use of the binocular operating microscope in ophthalmic surgery has highlighted both the desirability of some form of support for the operating surgeon's arms and the need for better fixation of the patient's head. Arm rests attached to the operating chair (Barraquer and Boberg-Ans, 1959) or to the operating table (Pierse, 1969) have been described. A more sophisticated mobile arm rest which maintains complete support of forearms and wrists has been described by Henderson, Pericic, and O'Brien (1970), who pointed out that hand tremor limits the finesse of microsurgical manoeuvres, and that, when using the operating microscope, the surgeon's arms and hands are necessarily in such a position that hand tremor will soon develop unless complete and comfortable support of the forearms and wrists is obtained.

Various devices have been described for supporting the patient's head, of which one in common use is the Ruben Pillow (Ruben, 1959).

A device which would both support the patient's head and provide hand support for the surgeon was felt to have some advantage. It is interesting to note that Dekking (1956), one of the early advocates of microsurgery, described such a support in prototype stage.

\section{Description and method of use}

The apparatus (Fig. I), which is designed to be used on the head support of an operating table, comprises a base-plate upon which are mounted two lateral supporting members, each of which carries a horizontal hand rest. The hand rest on the side of the eye for operation is narrower than that on the opposite side. This allows the hand on the operating side to work from below the level of the rest when desired.

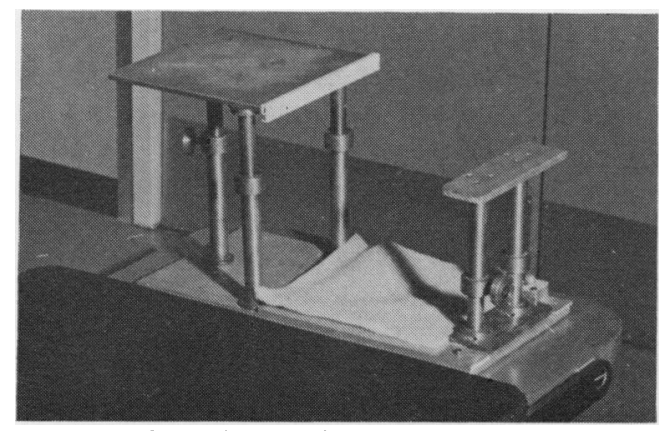

FIG. I General view of apparatus

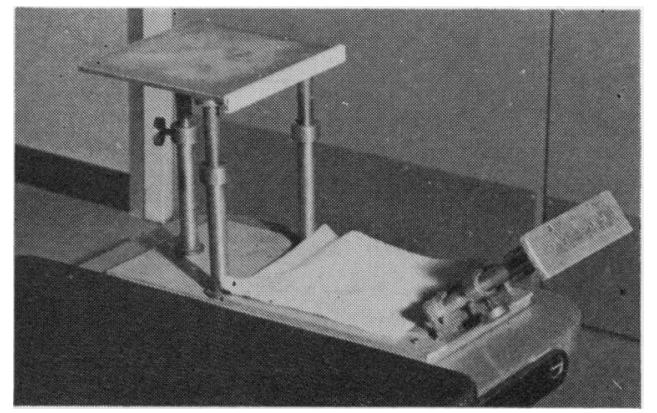

FIG. 2 Hinged side which opens to admit patient's head

Both supporting members are easily adjustable on slides for height and width. The support on the operating side is hinged on the base-plate (Fig. 2) to allow easy admission and removal of the patient's head. A simple locking-pin maintains the support in the vertical position during use.

The patient's head is supported between the small padded vertical surfaces on the medial aspects of the hand rests, with the occiput resting in a shallow groove in the base-plate, thus limiting fore-and-aft movement (Fig. 3, opposite). 
The device is designed to be reversible and is placed on the head support of the operating table so that the hinged member is on the side of the eye for operation. With the hinge in the open position the head of the already anaesthetized patient is introduced, so that the back of the head rests in the groove on the baseplate. The hinge is then closed and the locking-pin secured. The sliding horizontal plate on the opposite side is then adjusted so that each side of the head is tightly supported. It is not necessary to clamp the head, as in a vice. Non-sedated patients for operation under local anaesthesia may complain of some sense of restriction, and then an even looser adjustment will be found to be perfectly adequate.

So arranged, both head and support are draped, a cut-away aperture exposing only the eye for operation. The microscope may be set up and the surgeon may leave to scrub confident that the relative positions of microscope and field will be maintained. With fixed microscopes, minor adjustments to the position of the field are easily made by moving the base-plate on its supporting surface. The broader surface on the off-side is a useful place for instruments in repeated use. In cases in which it is desirable or necessary to operate from the side, an additional hand rest is easily attached to cross the top of the patient's head (Fig. 4).

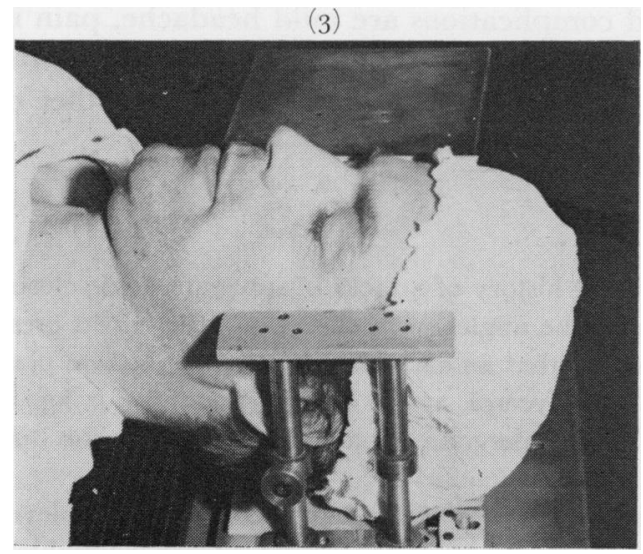

FIG. 3 Position of head with hand supports each side

FIG. 4 Additional hand rest for use when operating from the side

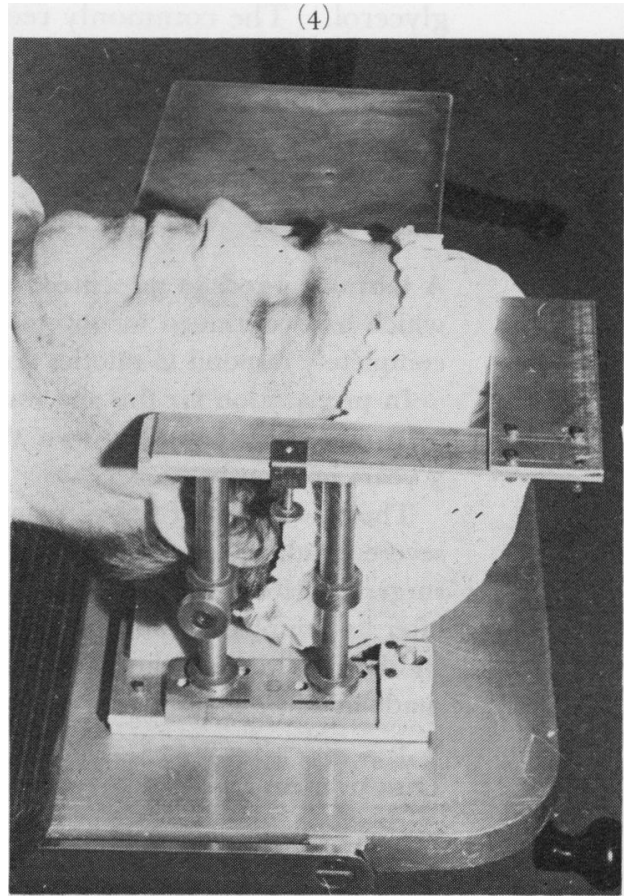

\section{Summary}

A simple head support provides fixation of the patient's head and support for the surgeon's hands.

The instrument was designed and produced as a project of the Microsurgical Instrumentation Research Association

\section{References}

BARRAQUer, J., and BoberG-ANs, J. (1959) Brit. F. Ophthal., 43, 69 DEKking, H. м. (1956) A.M.A. Arch. Ophthal., 55, I 14

henderson, P. N., Pericic, L. J., and o'Brien, B.McG. (1970) Med. F. Aust., 1, 720 PIERSE, D. (1969) "Microsurgery and Keratoplasty" in "Proceedings of II International Corneo-

Plastic Conference, 1967", ed. P. V. Rycroft, p. 341. Pergamon Press, Oxford RUBEN, с. м. (I.959) Brit. J. Ophthal., 43, I I 7 